\title{
Análise do Projeto de Extensão de Inclusão Digital e Informática Educativa no Ensino Fundamental da Rede Pública
}

\author{
Maria Rafaelly F. Alves ${ }^{1}$, Ricardo de S. Farias ${ }^{1}$, Kaique R. de S. Oliveira ${ }^{1}$, Valter \\ G. de M. Junior ${ }^{1}$, Wanderley P. de Sousa ${ }^{1}$, Jannayna Domingues B. Filgueira ${ }^{1}$ \\ ${ }^{1}$ Universidade Estadual da Paraíba (UEPB) Campus VII - Patos - PB - Brasil \\ \{rafaellyfalves, ricardofariasxyz, kaiquerijkaardcc, \\ wanderleysousapereira, jannadb\}@gmail.com, valtergmj@hotmail.com
}

\begin{abstract}
This article deals with the experience of the students of a higher education institution in the project of Digital Inclusion and Educational Informatics in the Public Primary School. With the objective of exposing and problematizing the use of computers by students of the public network, exposing questions of digital inclusion, informatics in education and the use of educational software. The extension project was carried out in the municipalities of Paulista, Pombal, São Mamede, and Teixeira in the state of Paraiba, aiming at Digital Inclusion of students from public schools.
\end{abstract}

Resumo. O presente artigo aborda a experiência vivenciada pelos alunos de uma instituição de nível superior no projeto de extensão Inclusão Digital e Informática Educativa no Ensino Fundamental da Rede Pública. Tendo como objetivo, expor e problematizar o uso da informática pelos alunos de rede pública, expondo questões de inclusão digital, informática na educação e o uso de softwares educacionais. $O$ projeto de extensão foi realizado nos municipios de Paulista, Pombal, São Mamede, e Teixeira do estado da Paraíba, visando a Inclusão Digital de alunos das escolas públicas.

\section{Introdução}

Ao longo dos anos, a informática vem sendo inserida em diferentes aspectos na vida das pessoas, sejam em suas casas, no trabalho ou na comunicação. Mesmo assim, existem pessoas que ainda não estão inclusas no meio digital, e outras que, apesar de incluídas, não sabem fazer o uso correto das tecnologias.

O ensino/aprendizado atrelado ao uso de tecnologias da informação apresenta dificuldades em países em desenvolvimento, como o Brasil. Segundo Filgueiras et al. (2016), é dever de um país que deseja seu crescimento, fazer com que todos sejam capazes de usar um computador, e através do seu uso, conseguir adquirir conhecimento.

A inclusão digital tem como o objetivo principal beneficiar as pessoas que não tem acesso às tecnologias de informação em seu cotidiano. Políticas de inclusão digital foram criadas com o intuito de minimizar o analfabetismo digital, como o Proinfo (Programa Nacional de Informática na Educação), criado pelo Ministério da Educação, cujo objetivo principal é introduzir o uso de tecnologias de informação e comunicação nas escolas de rede pública. 
Desta forma, o presente estudo tem como objetivo, promover uma discussão sobre a informática para crianças e jovens de escolas públicas, promovendo a inclusão digital e a informática na educação, a partir de uma experiência didática realizada com turmas de alunos em escolas dos municípios de Paulista, Pombal, São Mamede e Teixeira, do estado da Paraíba, ofertado por uma instituição de ensino superior.

\section{Inclusão Digital}

Pode-se julgar a inclusão digital como a democratização do alcance às tecnologias, permitindo o indivíduo da sociedade entrar na era tecnológica. Dessa maneira, ele pode desempenhar um papel ativo e interativo na sociedade, mediante a aproximação da tecnologia em suas atividades profissionais, cotidianas, educacionais, culturais, etc. Para ocorrer a inclusão digital, faz-se necessários três elementos básicos, que são: o computador, acesso à rede e o domínio dessas ferramentas [Vizentin 2016].

A inclusão digital enfrenta barreiras como a escolaridade e nível social, mas, com o desenvolvimento constante da tecnologia essas barreiras acabam diminuindo. A maior parte das pessoas possuem um smartphone, normalmente conectado à internet, tanto por redes wifi ou dados móveis, podendo considerar como um ponto positivo, uma vez que, as pessoas já detêm o acesso à informação. Entretanto, não basta apenas está conectado à internet com o dispositivo, faz-se necessário aprender e dominá-lo para a realização das tarefas, utilizando corretamente suas ferramentas e recursos.

\section{Tecnologias de Informação e de Comunicação}

As Tecnologias de Informação e de Comunicação (TIC), Segundo Bohn (2011) mencionado por Castilho (2015), é a combinação das telecomunicações com a informática, e das mídias eletrônicas que se adequa no método educacional como um todo, por meio de ferramentas.

De acordo com Geraldi e Bezelli (2015), a tecnologia da informação e da comunicação inserida na sociedade, resultou em várias modificações para o ser humano, visto que, com elas, pode-se absorver conhecimento de qualquer localização, possibilitando e facilitando a permuta de informações entre as pessoas, independente do formato ou distância envolvida.

\section{Informática Educativa}

Pode-se caracterizar a informática educativa como uma ferramenta em que o docente faz uso para auxiliá-lo em suas aulas. Os recursos digitais vêm tornando o processo de ensino e aprendizagem cada vez mais construtivas e informatizada [Brezolin et al. 2018].

Segundo Teixeira (2017), com a informática é possível se comunicar, fazer pesquisas, criar desenhos, realizar cálculos, digitar textos, entre outros. O computador pode trazer muitos benefícios e utilidades que podem ser utilizados no processo pedagógico. A partir da sua utilização é capaz de tornar as aulas mais criativas, que despertam nos alunos a curiosidade e a vontade de aprender. A internet pode auxiliar no processo de aprendizagem em sala de aula ou fora dela. Além do aprendizado, a informática pode propiciar outros benefícios, como o desenvolvimento social, atividades 
VIII Congresso Brasileiro de Informática na Educação (CBIE 2019)

Anais do XXV Workshop de Informática na Escola (WIE 2019)

de forma prática, ambientes mais dinâmicos e ativos, motivação, criatividade, curiosidade e habilidades de comunicação [Teixeira 2017].

\section{Metodologia}

O projeto foi realizado em cinco etapas com objetivo de proporcionar a inclusão digital aos alunos da rede pública.

A primeira etapa do projeto, possibilitou aos alunos o contato com a informática, conhecendo seus conceitos básicos, história da computação, componentes do computador (hardware) e sobre os sistemas operacionais e aplicações (software). Desta forma, na segunda etapa, os alunos tiveram contato direto com os computadores fazendo uso do sistema operacional e softwares instalado. Durante a terceira e quarta etapa, foi lecionado o pacote do BrOffice que conta com programas de edição de texto, planilhas eletrônicas e criação de apresentações.

A última etapa do projeto consistiu na explicação do uso adequado da internet, bem como a introdução a lógica de programação utilizando o Scratch, ferramenta esta, que permite a criação de jogos, animações e histórias de forma intuitiva por meio de blocos virtuais.

Assim, a metodologia utilizada nesta pesquisa, inicialmente foi de cunho bibliográfica, baseando-se em autores como Filgueiras et al. (2016). Posteriormente, conforme Gil (1999), constitui-se em um estudo de caso, desenvolvido na realização do projeto intitulado "Inclusão Digital e Informática Educativa no Ensino Fundamental da Rede Pública", que foi realizado no laboratório de uma escola, nos municípios de Paulista, Pombal, São Mamede e Teixeira, localizados no estado da Paraíba, em uma turma multisseriada, do ensino fundamental I e II.

\section{Resultados e Discussões}

$\mathrm{Na}$ educação, a informática vem beneficiando os alunos que têm acesso a suas ferramentas, pensando nisso, o projeto de extensão informática educativa no ensino fundamental da rede pública, foi criado com o intuito de transferir conhecimentos sobre informática básica e lógica de programação para os alunos do ensino fundamental.

Inicialmente participaram 72 alunos, entre 8 e 14 anos, de escolas públicas de ensino fundamental, nos municípios de Paulista, Pombal, São Mamede e Teixeira. No decorrer do curso desistiram 22 alunos, deste modo, ao fim do projeto foram aprovados 50 alunos.

Ao iniciar o projeto nas escolas, na primeira e segunda etapa, observou-se a necessidade que os alunos tinham de conhecer os conceitos básicos e a utilização do computador, o desenvolvimento histórico dos computadores até a sociedade atual e sobre o software e o hardware. Durante a terceira e quarta etapa, os alunos aprenderam a utilizar as ferramentas do pacote BrOffice, disponibilizadas pelo sistema Linux Educacional, sendo elas, o editor de texto, editor de planilha eletrônica e editor de apresentação. Neste processo, eles apresentaram dificuldades no manuseio do teclado e mouse, quando começaram a praticar com as ferramentas mencionadas anteriormente. Dificuldades essas que foram sendo superadas devido a execução das atividades. A Figura 1 ilustra os alunos utilizando os computadores. 
VIII Congresso Brasileiro de Informática na Educação (CBIE 2019)

Anais do XXV Workshop de Informática na Escola (WIE 2019)

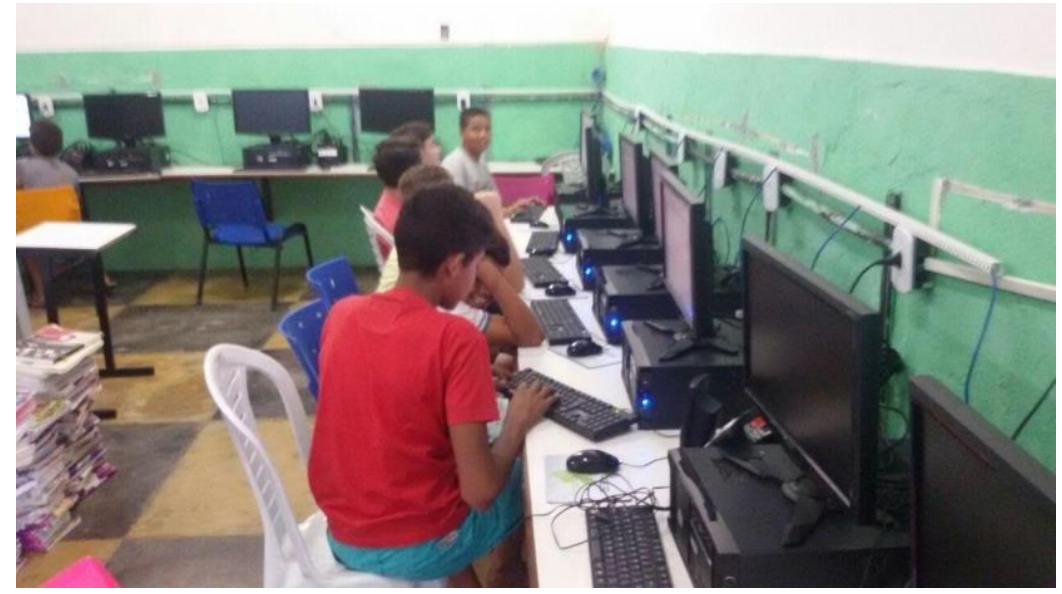

Figura 1. Alunos do projeto utilizando o computador, Pombal-PB.

$\mathrm{Na}$ última etapa o projeto chamou atenção dos alunos, pois, o uso adequado da internet transporta um conjunto de possibilidades para os alunos descobrirem e transformarem sua realidade através de pesquisas, redes sociais e sites educacionais. Por outro lado, ao iniciar a introdução a lógica de programação, os alunos demonstraram dificuldades em compreender sobre o conceito de programação e a prática, mas, ao utilizar a ferramenta Scratch, eles apresentaram interesse por ser um modo divertido de aprender a implementação dos algoritmos.

No Gráfico 1 , observa-se que, $60 \%$ das crianças beneficiadas com o projeto de extensão, não apresentaram dificuldade durante o processo de aprendizagem, $30 \%$ apresentaram dificuldades medianas, onde conseguiam entender e aplicar os assuntos lecionados com um de pouco de dificuldade, e apenas $10 \%$ apresentaram dificuldades significativas, em que os conceitos e práticas tinham que ser explicados de diversas formas diferentes para que conseguissem compreender.

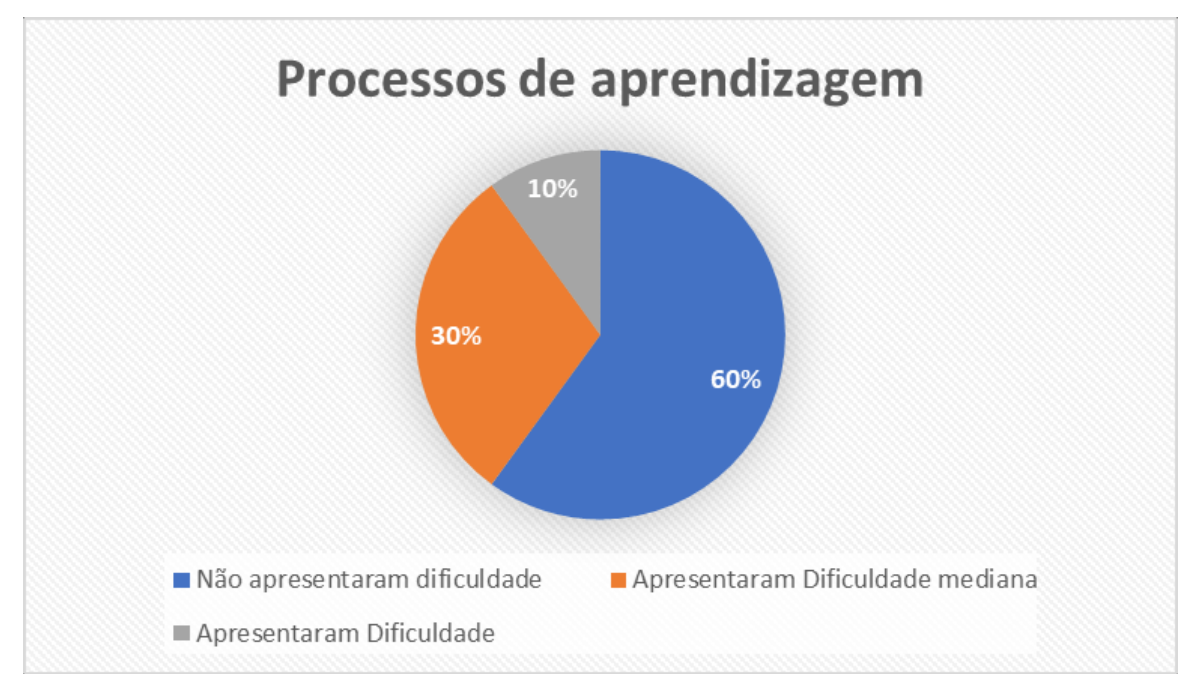

\section{Gráfico 1. Pesquisa de campo do processo de aprendizado dos alunos participantes.}

A informática beneficia os alunos de escolas públicas, tanto em sala de aula quanto fora delas. O uso da informática é uma forma de ceder a oportunidade de construir conhecimento com o uso das ferramentas dos computadores, utilizando-as da forma correta. Os resultados encontrados no presente estudo, demonstram a importância de projetos de extensão que deem acesso a informática as crianças de escolas públicas. 
Nota-se também que, a utilização de sistemas operacionais educativos é de suma importância para o ensino/aprendizado de crianças, bem como a introdução à lógica de programação que abre um leque de possibilidade para os professores incentivarem os alunos a desenvolverem seu raciocínio lógico.

\section{Conclusão}

Aos devidos fins desta pesquisa, é possível notar a importância de projetos de inclusão digital para alunos do ensino fundamental de escolas públicas, como o projeto de extensão: informática educativa no ensino fundamental da rede pública, ofertado por uma instituição de ensino superior.

Ao fim do projeto, foram constatados na prática, os benefícios e desafios da informática para crianças de ensino público. Entre os benefícios, pode-se citar o uso de ferramentas educacionais em sala de aula, pois, elas auxiliam no aprendizado dos alunos. Em contrapartida, um desafio encontrado foi a falta de manutenção dos laboratórios de informática, por isso, um número maior de alunos não foram atendidos. Para os graduandos, esse projeto auxiliou na formação social, acadêmica e no desenvolvimento de competências e no incentivo à docência.

\section{Referências}

Brezolin, F., et al. (2018) "Dispositivo IoT lúdico para monitoramento de variáveis ambientais: Uma experiência de aplicação no ensino fundamental”, In: Brazilian Symposium on Computers in Education (Simpósio Brasileiro de Informática na Educação-SBIE). p. 91.

Castilho, L. B. (2018) "O uso da Tecnologia da Informação e Comunicação (TIC) no processo de ensino e aprendizagem em cursos superiores", Projetos e Dissertações em Sistemas de Informação e Gestão do Conhecimento, v. 4, n. 2.

Cavalcante, R. B., et al. (2017) "Inclusão digital e uso de tecnologias da informação: a saúde do adolescente em foco", Perspectivas em Ciência da Informação, 22(4), 3-21.

Filgueira, A. W. N., et al. (2016) "Linux Educacional-uma ferramenta a ser descoberta na rede pública", In: Anais do Encontro Virtual de Documentação em Software Livre e Congresso Internacional de Linguagem e Tecnologia Online.

Geraldi, L. M. A. e Bizelli, J. L. (2015) "Tecnologias da informação e comunicação na educação: conceitos e definições”, Revista online de Política e Gestão Educacional, n. 18.

Gil, A. C. (1999) "Métodos e técnicas de pesquisa social”, São Paulo: Atlas.

Teixeira. É. A. (2017) "Os Impactos da Informática na Educação Infantil e na Sociedade".

Vizentin, C. et al. (2016) “A importância do letramento digital na escola e na sociedade e os seus diferentes conceitos". 